\title{
Origin and insertion of the medial patellofemoral ligament: a systematic review of anatomy
}

\author{
Arash Aframian ${ }^{1,2,3}$ - Toby O. Smith ${ }^{4} \cdot$ T. Duncan Tennent ${ }^{1,2} \cdot$ Justin Peter Cobb $^{3}$. \\ Caroline Blanca Hing ${ }^{1,2}$
}

Received: 4 March 2016 / Accepted: 3 August 2016 / Published online: 8 September 2016

(C) The Author(s) 2016. This article is published with open access at Springerlink.com
Abstract
Purpose The medial patellofemoral ligament (MPFL) is the major medial soft-tissue stabiliser of the patella, origi- nating from the medial femoral condyle and inserting onto the medial patella. The exact position reported in the litera- ture varies. Understanding the true anatomical origin and insertion of the MPFL is critical to successful reconstruc- tion. The purpose of this systematic review was to deter- mine these locations.
Methods A systematic search of published (AMED, CINAHL, MEDLINE, EMBASE, PubMed and Cochrane Library) and unpublished literature databases was con- ducted from their inception to the 3 February 2016. All papers investigating the anatomy of the MPFL were eligi- ble. Methodological quality was assessed using a modified CASP tool. A narrative analysis approach was adopted to synthesise the findings.
Results After screening and review of 2045 papers, a total of 67 studies investigating the relevant anatomy were included. From this, the origin appears to be from an area rather than (as previously reported) a single point on the medial femoral condyle. The weighted average length was $56 \mathrm{~mm}$ with an 'hourglass' shape, fanning out at both liga- ment ends.
Arash Aframian
arash.aframian@gmail.com
1 Trauma and Orthopaedics Department, 5th Floor St James' Wing, St George's University Hospitals NHS Foundation Trust, Blackshaw Road, London SW17 0QT, UK
2 St George's, University of London, London SW17 ORE, UK
3 Imperial College, London W6 8RP, UK
4 Faculty of Medicine and Health Sciences, University of East Anglia, Norwich NR4 7TJ, UK
Conclusion The MPFL is an hourglass-shaped struc- ture running from a triangular space between the adduc- tor tubercle, medial femoral epicondyle and gastrocne- mius tubercle and inserts onto the superomedial aspect of the patella. Awareness of anatomy is critical for assess- ment, anatomical repair and successful surgical patellar stabilisation.
Level of evidence Systematic review of anatomical dissec- tions and imaging studies, Level IV.
Keywords Medial patellofemoral ligament - Anatomy · Insertion · Origin · MPFL · Attachments · Reconstruction
Abbreviations
AA Arash Aframian
AMT Adductor magnus tendon
AT Adductor tubercle
CASP Critical appraisal skills programme
$\mathrm{CH} \quad$ Caroline Hing
CT Computed tomography
DT Duncan Tennent
MeSH Medical subject headings
JC Justin Cobb
LPD Lateral patellar dislocation
LPFL Lateral patellofemoral ligament
MCL Medial collateral ligament
MFE Medial femoral epicondyle
MPFL The medial patellofemoral ligament
MRI Magnetic resonance imaging
PRISMA Preferred reporting items for systematic reviews and meta-analyses
USS Ultrasound scan
SD Standard deviation
TOS Toby O Smith
VMO Vastus magnus obliquus 


\section{Introduction}

Patellar dislocation is multi-factorial in aetiology and may involve abnormalities of the bone or soft tissues [82]. The medial patellofemoral ligament (MPFL) is a band of retinacular tissue within layer II of the medial side of knee and as the main medial soft tissue stabiliser of the patella (particularly in early flexion) is critical for tracking and stability in the trochlear groove $[38,66,69$, $81,88,101]$. Acute lateral patellar dislocation (LPD) is associated with MPFL rupture in $87-100 \%$, and the significant number of different procedures to treat the problem highlights the limitations in understanding and management $[5,20,54,77]$.

Longer term, patellar instability and dislocation are associated with chondral injury and osteoarthritis [28, 54]. Non-operative management can leave $33 \%$ with significant patient-reported symptoms, $44 \%$ with at least one episode of further dislocation and $52 \%$ of patients unable to return to vigorous sports at an average of 11.8-year followup [20]. Surgery can correct recurrent dislocation which untreated can occur in $42-49 \%$ of patients [20,55].

Reconstruction of the MPFL is now an accepted technique for the treatment of patellofemoral instability when soft tissues rather than bony morphology are the primary pathological feature $[18,29,74,88]$. Performed non-anatomically, it can lead to non-physiological patellofemoral loads and kinematics which may lead to pain and increased chondral injury [7, 30, 79, 95].

Although Weber and Weber first described the anatomy of the knee in 1836, there remains no consensus on the anatomy of the MPFL or even its existence, which has been reported to be present in 35-100\% of cadaveric specimens [21, 63, 71, 76, 99]. Understanding of MPFL origin and insertion points is fundamental for functional reconstruction of the ligament thus reducing the risk of subsequent repeated instability, maltracking and osteoarthritis [45].

The aim of this study was to conduct a systematic review of the literature to define the anatomy of the MPFL.
An accurate definition of MPFL anatomy enables assessment of MPL injuries and planning anatomical reconstruction of the MPFL to restore tracking without overloading the patellofemoral joint.

\section{Materials and methods}

\section{Search strategy}

An electronic PRISMA compliant [59] search was conducted on the 3 February 2016 from database inceptions to the search date. Databases searched included Embase, AMED, Medline, PsycINFO, Cochrane, CINAHL, PubMed and NHS Evidence. Where available, medical subject headings (MeSH) terms were used. In addition, searches of grey literature were conducted using Google Scholar, Web of Science, OpenGrey, Ethos and the Zetoc engines. Search terms used for the MEDLINE search are presented in Table 1 . This strategy was modified for the other database searches. The reference lists of all potentially eligible papers were also reviewed to identify any additional studies.

\section{Eligibility criteria and identification}

Inclusion eligibility was confirmed if publications investigated the anatomy of the MPFL, specifically origin or insertion points in human subjects. Where inclusion could not be determined from the title and subsequently abstract, the full paper was retrieved as shown in Fig. 1. Assessment of anatomy was permitted either surgically or radiologically. Papers were excluded if MPFL anatomy had been based on other data sources. Studies were eligible irrespective of language, age or country of origin.

The electronic searches were independently performed by two authors (AA, TOS). Based on the eligible criteria, the two reviewers (AA, TOS) independently screened the search results to identify potentially eligible papers. The

Table 1 Search strategy terms for the literature search of anatomy of the medial patellofemoral ligament using MEDLINE (via OVID)

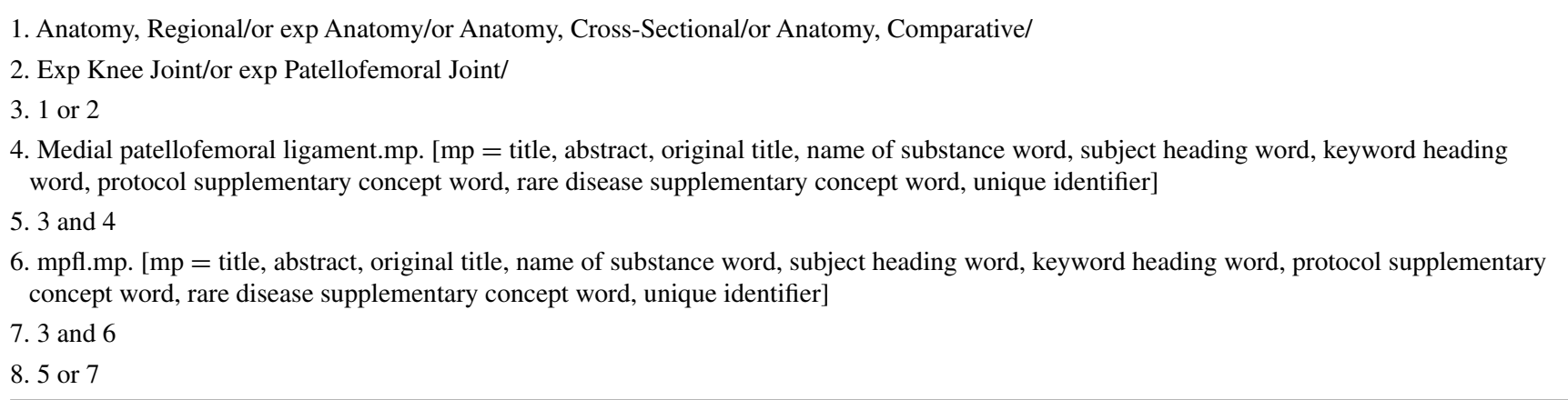




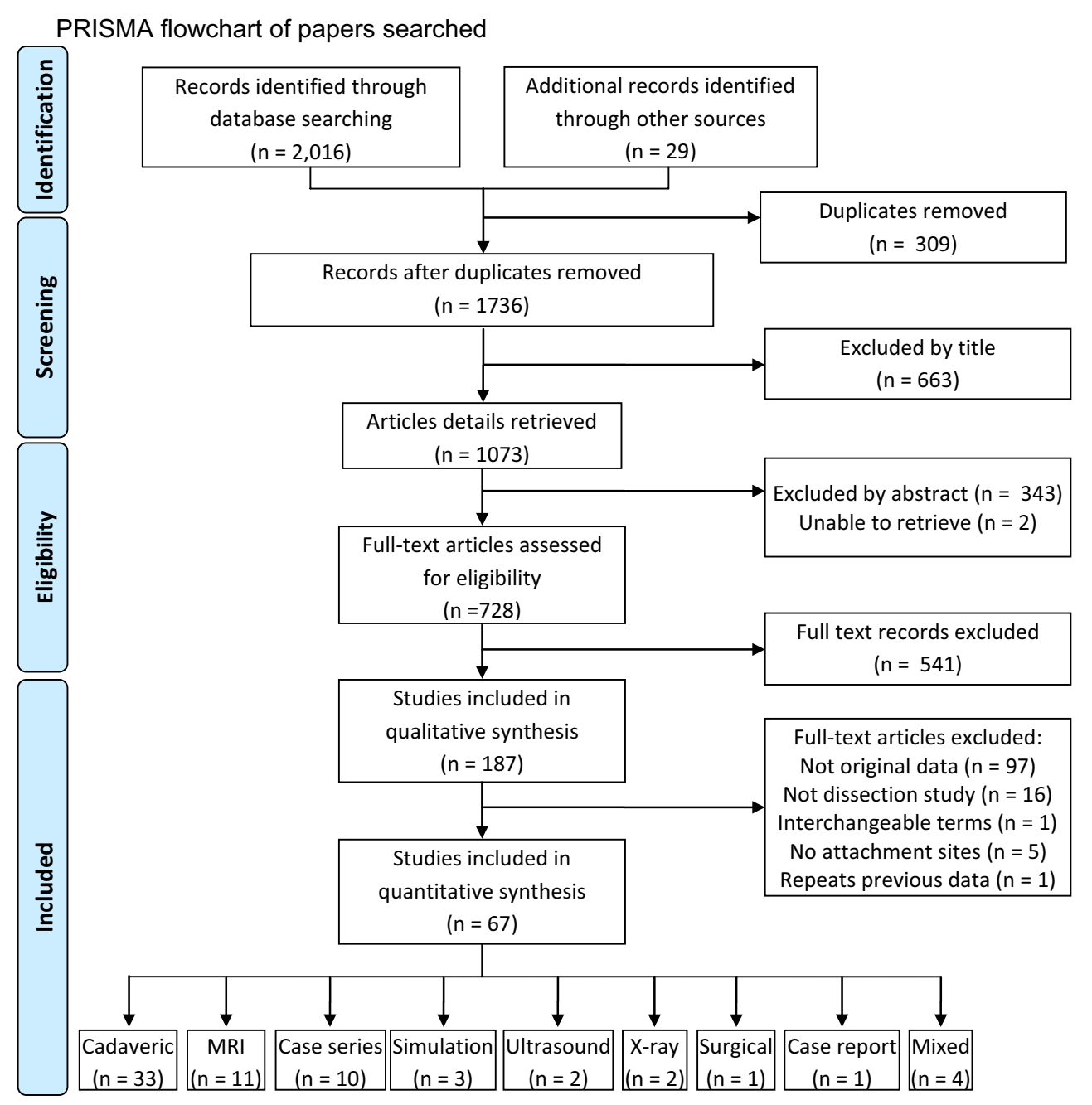

Fig. 1 PRISMA flowchart of papers searched

full-texts of all provisional papers were obtained, and a decision of final eligibility was made after reviewing these by the two reviewers (AA, TOS).

\section{Data extraction and critical appraisal}

Data extraction was made by one reviewer (AA) and repeated by a second reviewer (TOS) to check and verify the findings and accuracy of the results-there was $100 \%$ agreement in data extracted (Fig. 1). All data were extracted into an electronic database. Data extracted included: country of origin, study type, whether the study was of normal or patellar dislocation knees and in cases following dislocation whether acute or recurrent, number of patients and knees, age, gender, preservation method (if cadaveric), MPFL identification rate and size, origin and insertion.
The quality of each included paper was evaluated using a modified critical appraisal skills programme (CASP) tool [89]. This was undertaken by one reviewer (AA) and verified by a second (TOS). Any disagreements in data extraction or quality assessment were resolved through discussion between the reviewers so that there was $100 \%$ agreement in the assessments of cadaveric and radiological or clinical papers (Tables 2, 3).

\section{Data analysis}

Due to multiple methodologies used in the included studies, there was a high degree of study heterogeneity, and therefore, a meta-analysis was inappropriate. Accordingly, a narrative analysis was adopted to determine the consensus on MPFL identification rate, MPFL size, and origin and insertion of the MPFL from the study cohorts. 


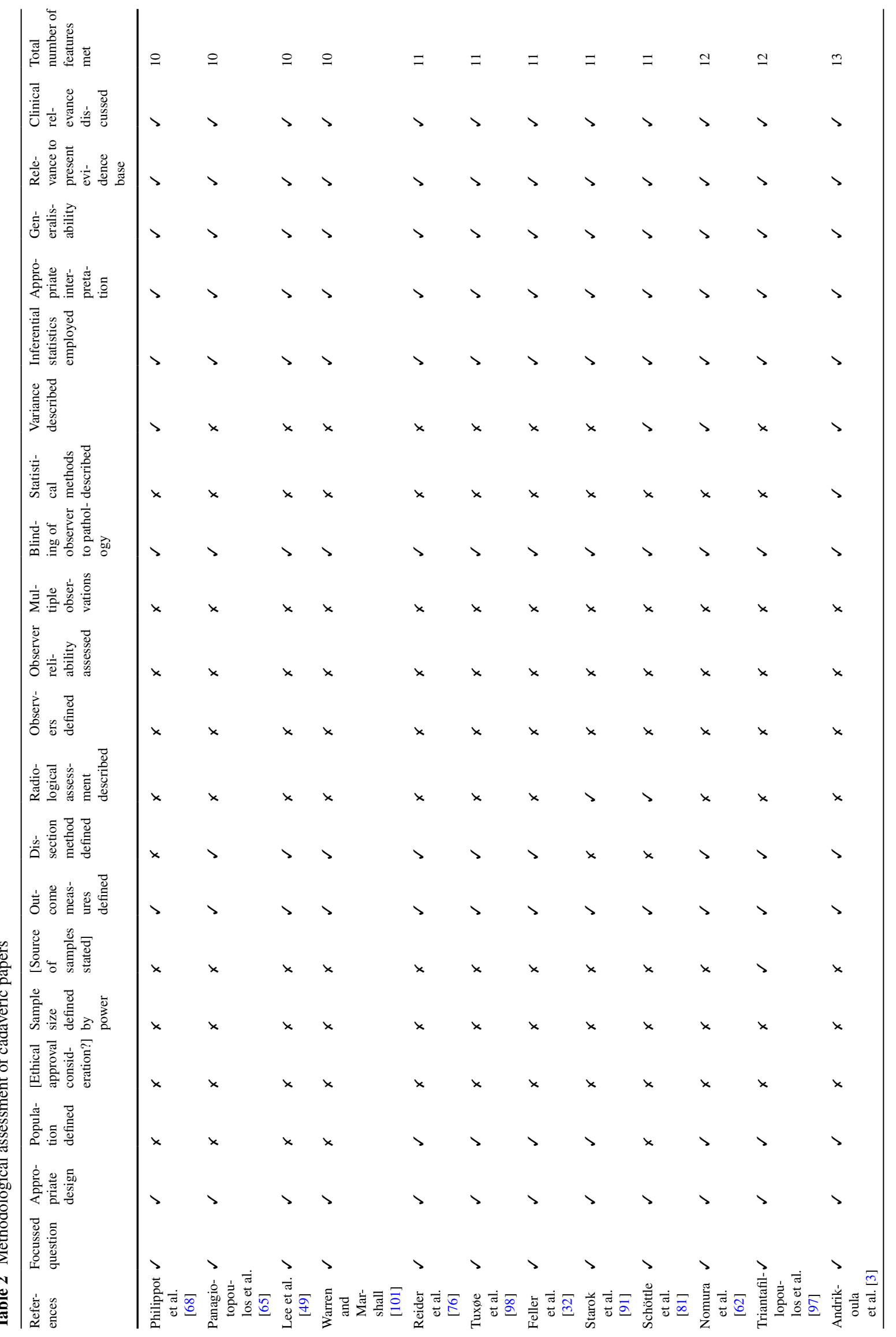




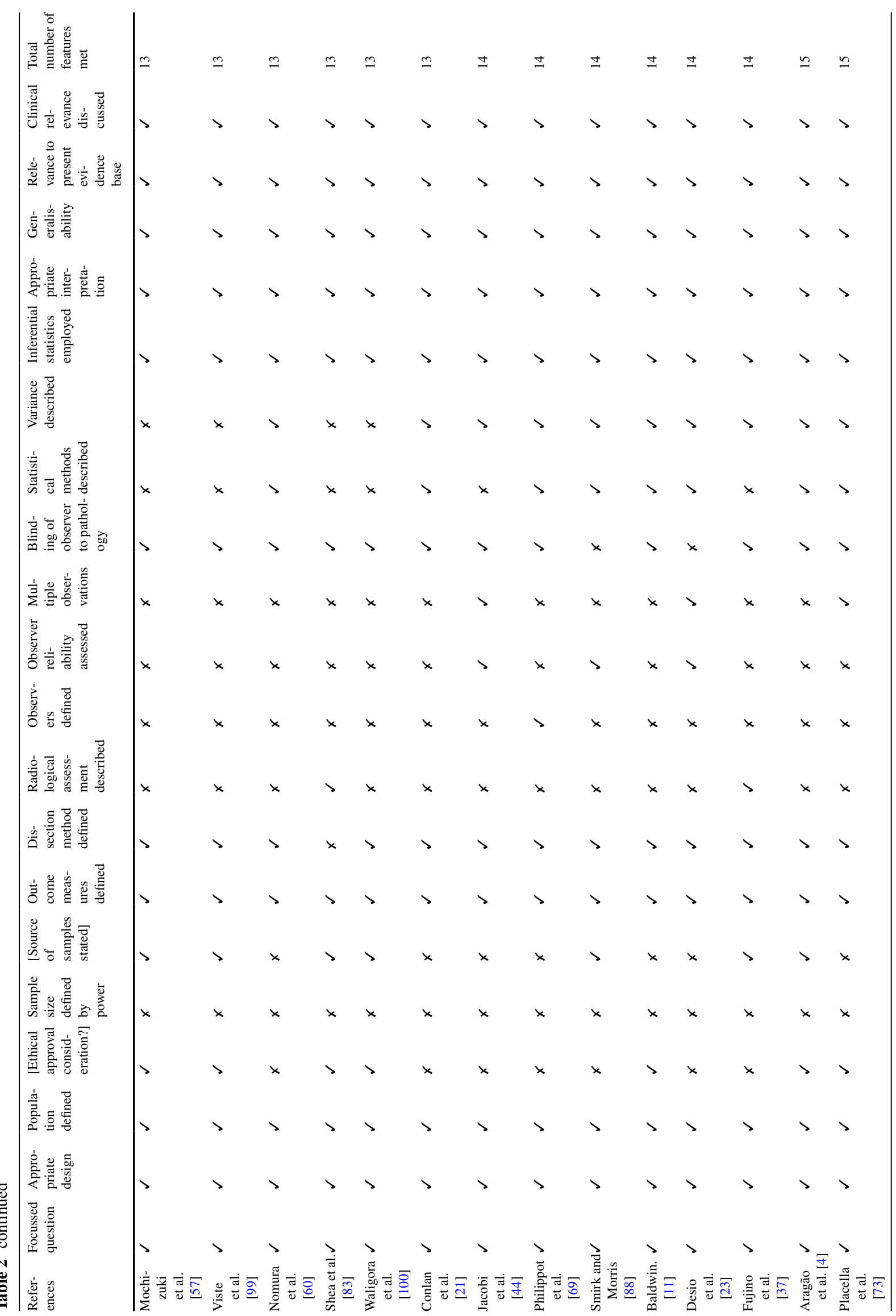




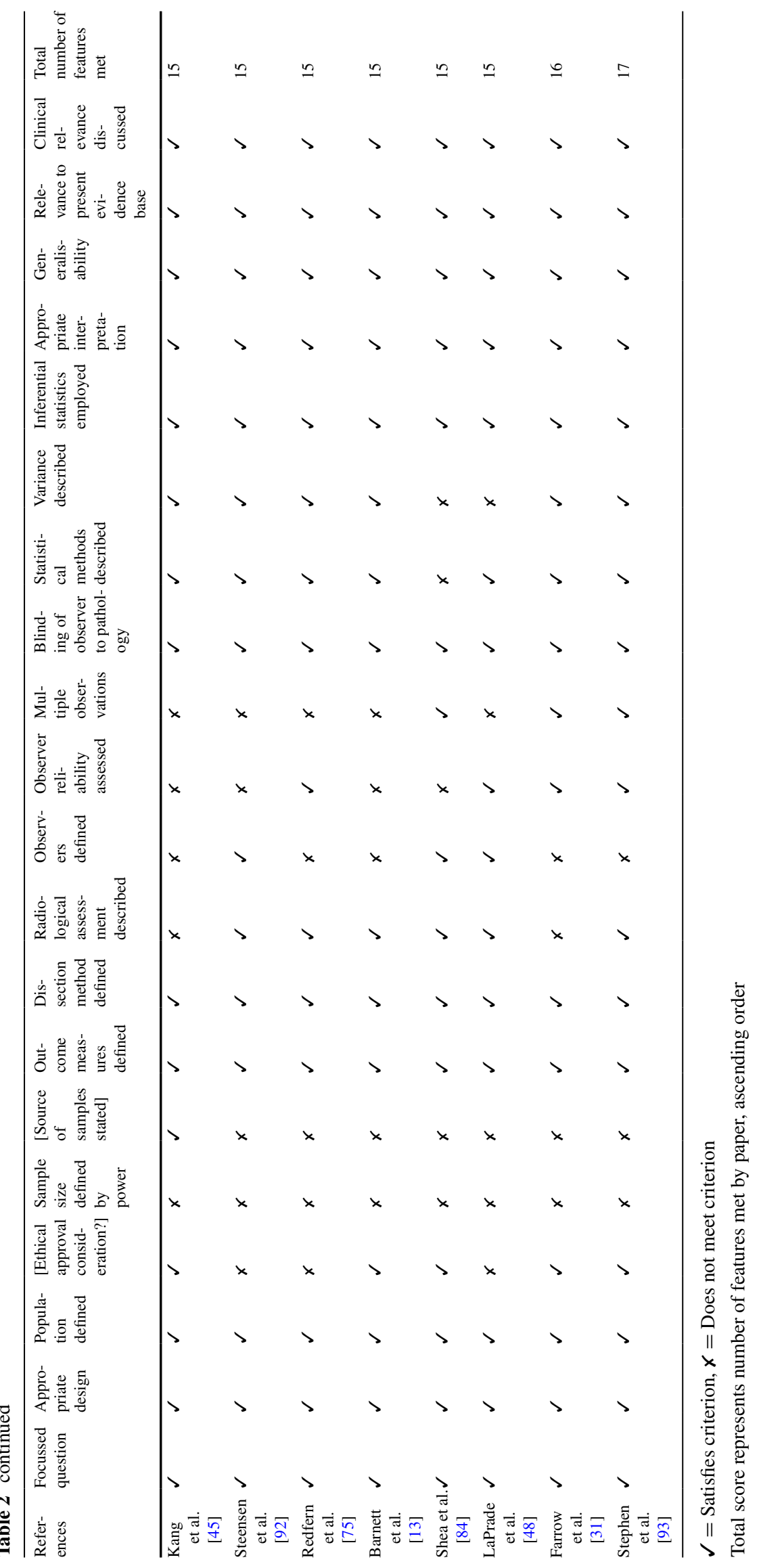




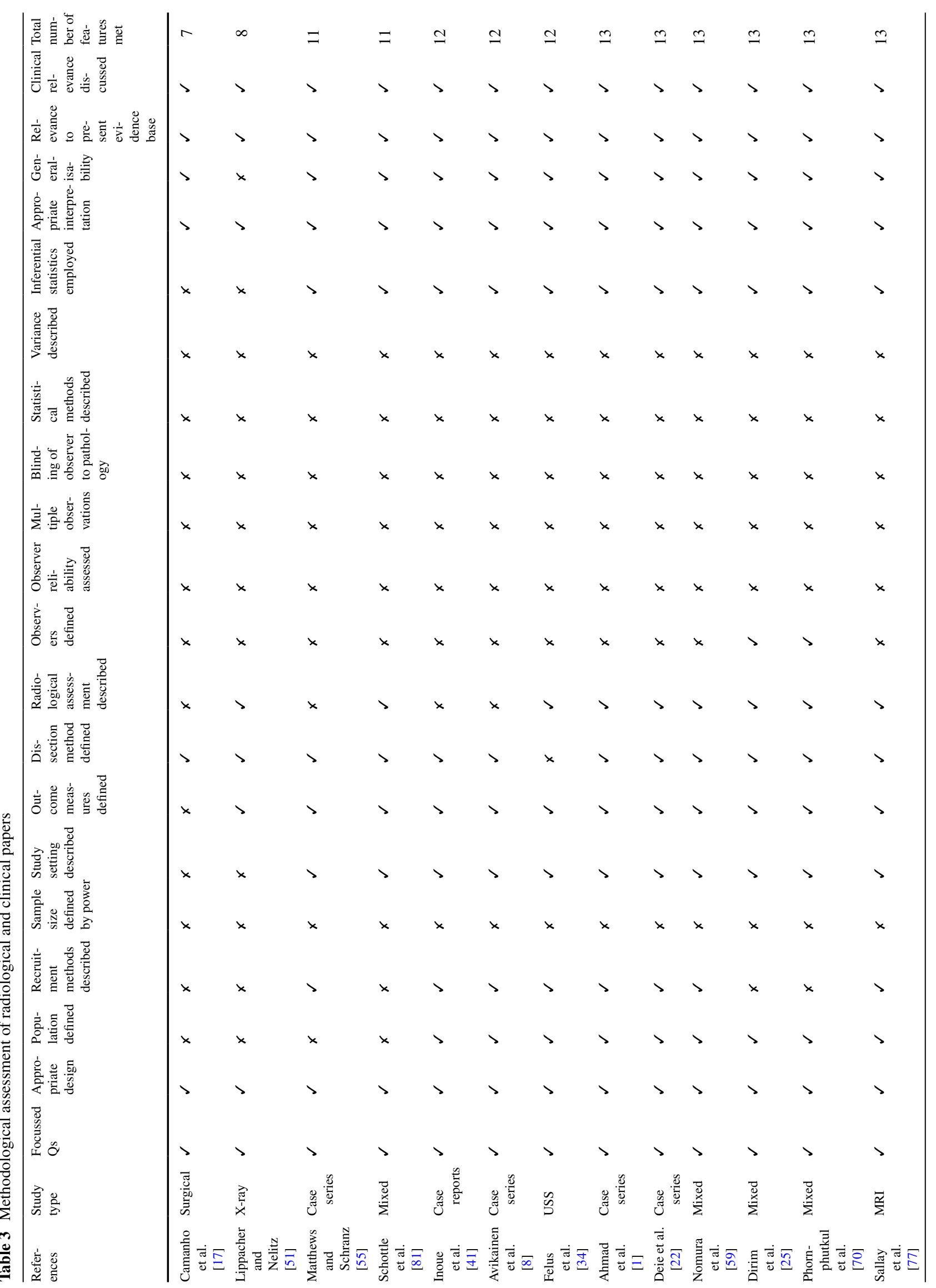




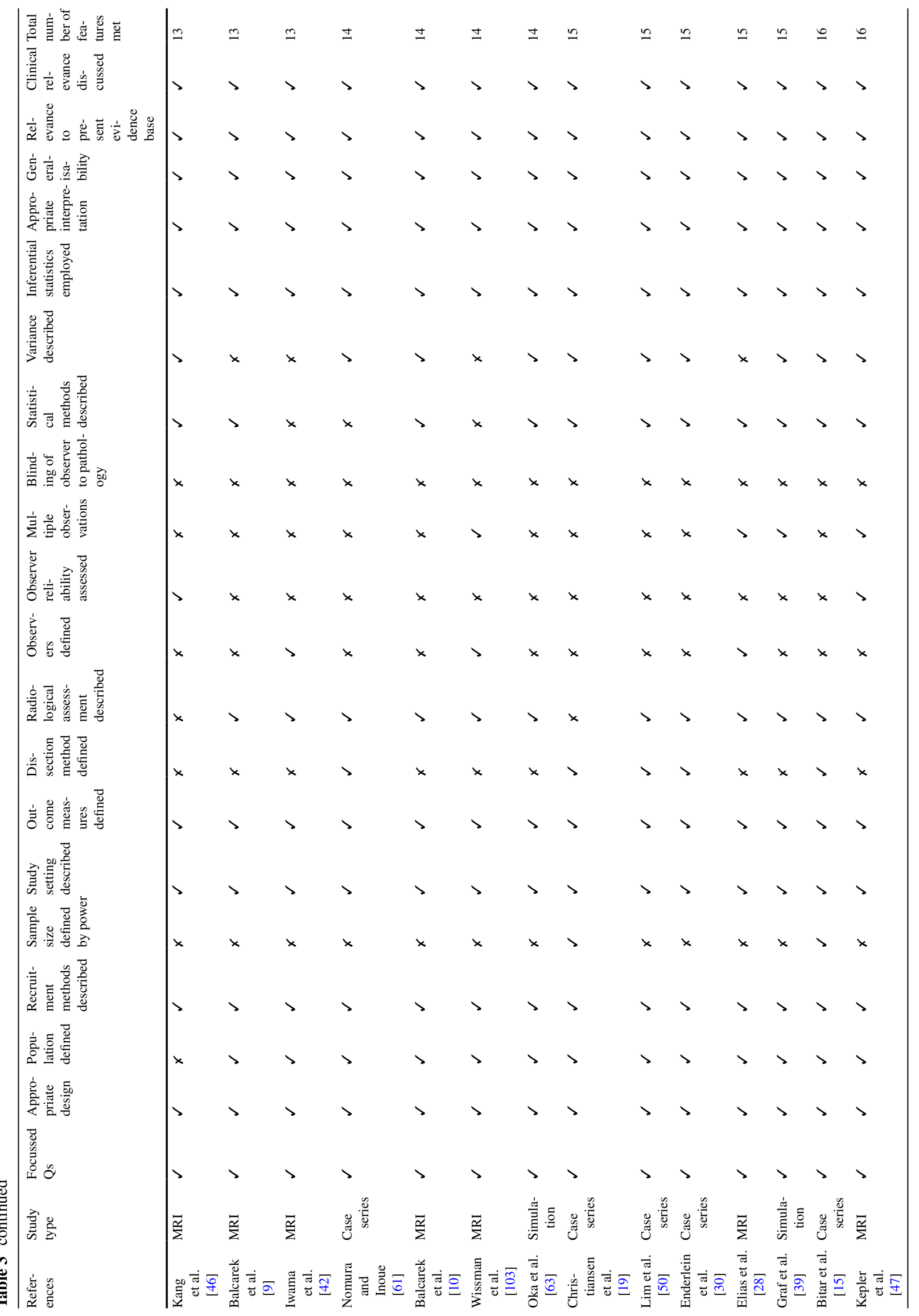




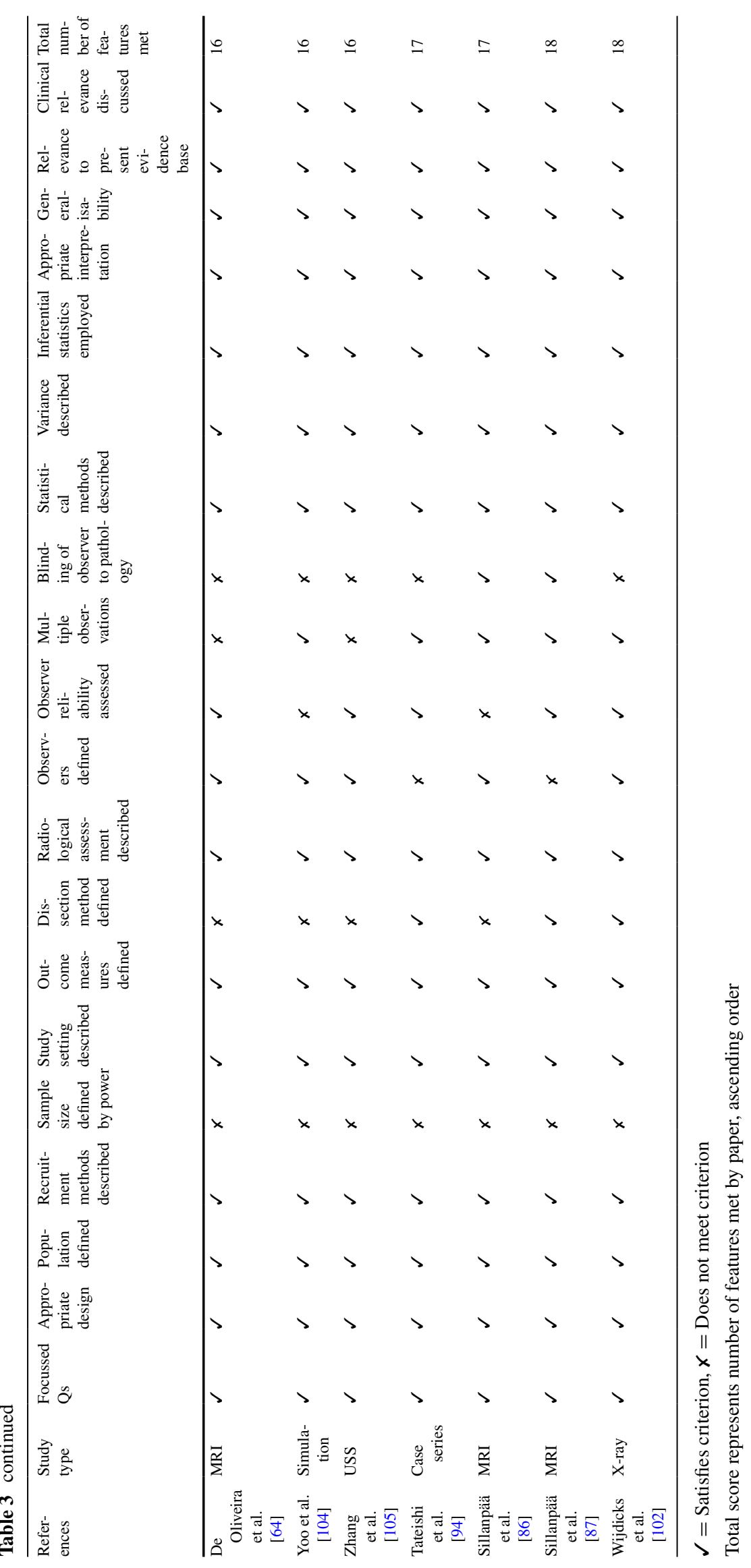




\section{Results}

\section{Search results}

A summary of the search results is presented in Fig. 1. A total of 2045 papers were identified. Of the 187 potentially relevant papers, 67 satisfied the inclusion criteria.

\section{Characteristics of included studies}

The 67 studies included 1950 knees where the MPFL was investigated in over 1475 patients (some cadaveric studies did not state whether the knees were from the same body). Where both the average age and number of patients were given (35 studies), the weighted average age was 33 years. Gender was given in 44 publications with 613 males (48\%) and 658 females $(52 \%)$. The 67 studies were from several countries and included 764 (39\%) normal, 507 (26\%) acute dislocation, 381 (20\%) recurrent dislocation and 289 $(15 \%)$ mixed pathology knees. Investigation technique was heterogeneous (Tables 4, 5).

\section{Characteristics by study design}

\section{Surgical studies}

Surgical technique or case series reports usually describe an approach rather than study anatomy (Tables 4, 5). Five studies were of acute patellar dislocation, and seven referred to recurrent patellar dislocation. Amongst the ten papers which did specify gender, nine papers included 76 male and 77 female subjects and a single case series which reported 78 male and 162 female knees, but only 224 participants indicating that some must be from the same participants [32]. Four studies were in adults, six were mixed age groups and one did not give the age of subjects [17]. One study looked at MPFL reconstruction in children [24]. Eight papers provided the average age, giving a weighted average of 21 years for adults ( 9 years for children). Due to expectation bias of surgical studies, these were excluded from the final analysis.

\section{Imaging studies}

Amongst the imaging studies, there was also heterogeneity (Tables 4, 5). Eight studies were of anatomy in acute patellar dislocation, one with recurrent patellar dislocation, one in patients without any history or evidence of patellofemoral instability and five studies were a mixture of these types. There was a large variation in subjects, with an age range of 12-89 years, and average ages of 14-72 years even within imaging modalities with the two radiographic studies reporting a large variation in age range $[53,102]$.
Table 4 Patellar insertions of the MPFL reported

\begin{tabular}{|c|c|c|}
\hline Site & References & $\begin{array}{l}\text { Number } \\
\text { of knees }\end{array}$ \\
\hline \multirow[t]{10}{*}{ Medial patella } & Panagiotopoulos et al. $[65]^{\mathrm{a}}$ & 8 \\
\hline & Mochizuki et al. [57] ${ }^{\mathrm{a}}$ & 16 \\
\hline & Lee et al. $[49]^{\mathrm{a}}$ & 5 \\
\hline & Starok et al. $[91]^{\mathrm{a}}$ & 5 \\
\hline & Waligora et al. [100] ${ }^{\mathrm{a}}$ & 18 \\
\hline & Matthews and Schanz $[55]^{\mathrm{e}}$ & 21 \\
\hline & Iwama et al. [42] $]^{\mathrm{c}}$ & 25 \\
\hline & Kang et al. $[46]^{\mathrm{c}}$ & 85 \\
\hline & Sillanpää et al. [86] ${ }^{\mathrm{c}}$ & 32 \\
\hline & Sillanpää et al. [87] ${ }^{\mathrm{c}}$ & 56 \\
\hline \multirow[t]{2}{*}{ Proximal } & Viste et al. [99] ${ }^{\mathrm{a}}$ & 12 \\
\hline & Wissman et al. $[103]^{\mathrm{c}}$ & 10 \\
\hline \multirow[t]{4}{*}{ Proximal half } & Jacobi et al. $[44]^{\mathrm{a}}$ & 20 \\
\hline & Philipott et al. [69] ${ }^{\mathrm{a}}$ & 23 \\
\hline & Conlan et al. $[21]^{\mathrm{a}}$ & 25 \\
\hline & Stephen et al. [93] ${ }^{\mathrm{a}}$ & 8 \\
\hline \multirow[t]{4}{*}{ Proximal one third } & Triantafillopoulos et al. [97] ${ }^{\mathrm{a}}$ & 8 \\
\hline & Placella et al. [73] ${ }^{\mathrm{a}}$ & 20 \\
\hline & Tateishi et al. $[94]^{\mathrm{e}}$ & 27 \\
\hline & Graf et al. $[39]^{\mathrm{d}}$ & 10 \\
\hline \multirow{2}{*}{$\begin{array}{l}\text { Proximal one third to } \\
\text { midline }\end{array}$} & Nomura et al. $[60]^{\mathrm{a}}$ & 17 \\
\hline & Nomura et al. [59] ${ }^{\mathrm{b}}$ & 27 \\
\hline \multirow[t]{3}{*}{ Middle } & Kang et al. $[45]^{\mathrm{a}}$ & 12 \\
\hline & Shea et al. $[84]^{\mathrm{a}}$ & 9 \\
\hline & Yoo et al. $[104]^{\mathrm{d}}$ & 10 \\
\hline \multirow[t]{8}{*}{ Proximal two thirds } & Tuxøe et al. [98] ${ }^{\mathrm{a}}$ & 39 \\
\hline & Andrikoula et al. $[3]^{\mathrm{a}}$ & 10 \\
\hline & Nomura et al. [62] ${ }^{\mathrm{a}}$ & 20 \\
\hline & Baldwin. $[11]^{\mathrm{a}}$ & 50 \\
\hline & Inoue et al. $[41]^{\mathrm{f}}$ & 2 \\
\hline & Christiansen et al. [19] $]^{\mathrm{e}}$ & 42 \\
\hline & Balcarek et al. $[10]^{\mathrm{c}}$ & 73 \\
\hline & Balcarek et al. $[9]^{\mathrm{c}}$ & 43 \\
\hline \multirow[t]{10}{*}{ Superomedial } & LaPrade et al. [48] ${ }^{\mathrm{a}}$ & 8 \\
\hline & Feller et al. [32] ${ }^{\mathrm{a}}$ & 20 \\
\hline & Desio et al. $[23]^{\mathrm{a}}$ & 9 \\
\hline & Barnett et al. $[13]^{\mathrm{a}}$ & 10 \\
\hline & Hautamaa et al. [40] ${ }^{\mathrm{a}}$ & 17 \\
\hline & Phornphutkul et al. [70] ${ }^{\mathrm{b}}$ & 5 \\
\hline & Dirim et al. $[25]^{\mathrm{b}}$ & 12 \\
\hline & De Oliveira et al. [64] ${ }^{c}$ & 125 \\
\hline & Zhang et al. $[105]^{\mathrm{g}}$ & 49 \\
\hline & Steensen et al. $[92]^{\mathrm{a}}$ & 11 \\
\hline \multirow{3}{*}{$\begin{array}{l}\text { Insertion fans out over } \\
\text { patella and surrounding } \\
\text { tissues }\end{array}$} & Fujino et al. $[37]^{\mathrm{a}}$ & 31 \\
\hline & Smirk and Morris $[88]^{\mathrm{a}}$ & 25 \\
\hline & Aragão et al. [4] ${ }^{\mathrm{a}}$ & 10 \\
\hline
\end{tabular}

Study type: ${ }^{\mathrm{a} C a d a v e r i c ;}{ }^{\mathrm{b}}$ Mixed; ${ }^{\mathrm{c}}$ MRI; ${ }^{\mathrm{d}}$ Simulation; ${ }^{\mathrm{e}}$ Series; ${ }^{\mathrm{f}}$ Case report; ${ }^{\mathrm{g}} \mathrm{USS}$ 
Table 5 Femoral origins of the MPFL reported

\begin{tabular}{|c|c|c|}
\hline Site & Papers & $\begin{array}{l}\text { Number } \\
\text { of knees }\end{array}$ \\
\hline Adductor tubercle (AT) & Starok et al. $[91]^{\mathrm{a}}$ & 5 \\
\hline \multirow[t]{8}{*}{ Distal to AT } & Smirk and Morris $[88]^{\mathrm{a}}$ & 25 \\
\hline & Viste et al. [99] ${ }^{\mathrm{a}}$ & 12 \\
\hline & Jacobi et al. $[44]^{\mathrm{a}}$ & 20 \\
\hline & Nomura et al. $[60]^{\mathrm{a}}$ & 17 \\
\hline & Tuxøe et al. [98] ${ }^{\mathrm{a}}$ & 39 \\
\hline & Nomura et al. $[62]^{\mathrm{a}}$ & 20 \\
\hline & Dirim et al. $[25]^{\mathrm{b}}$ & 12 \\
\hline & Lim et al. $[50]^{\mathrm{b}}$ & 27 \\
\hline \multirow{7}{*}{$\begin{array}{l}\text { Medial femoral epicon- } \\
\text { dyle (MFE) }\end{array}$} & Panagiotopoulos et al. $[65]^{\mathrm{a}}$ & 8 \\
\hline & Mochizuki et al. [57 ${ }^{\mathrm{a}}$ & 16 \\
\hline & Andrikoula et al. $[3]^{\mathrm{a}}$ & 10 \\
\hline & Steensen et al. $[92]^{\mathrm{a}}$ & 11 \\
\hline & Reider et al. [76] ${ }^{\mathrm{a}}$ & 48 \\
\hline & Hautamaa et al. $[40]^{\mathrm{a}}$ & 17 \\
\hline & Kang et al. $[46]^{\mathrm{c}}$ & 85 \\
\hline \multirow[t]{22}{*}{ Between MFE and AT } & Philippot et al. [69] ${ }^{\mathrm{a}}$ & 23 \\
\hline & Placella et al. $[73]^{\mathrm{a}}$ & 20 \\
\hline & Laprade et al. [48] ${ }^{\mathrm{a}}$ & 8 \\
\hline & Fujino et al. [37] ${ }^{\mathrm{a}}$ & 31 \\
\hline & Stephen et al. $[93]^{\mathrm{a}}$ & 8 \\
\hline & Baldwin $[11]^{\mathrm{a}}$ & 50 \\
\hline & Farrow et al. [31] ${ }^{\mathrm{a}}$ & 16 \\
\hline & Lee et al. $[49]^{\mathrm{a}}$ & 5 \\
\hline & Waligora et al. $[100]^{\mathrm{a}}$ & 18 \\
\hline & Kang et al. $[45]^{\mathrm{a}}$ & 12 \\
\hline & Barnett et al. [13] ${ }^{\mathrm{a}}$ & 10 \\
\hline & Schöttle et al. $[81]^{\mathrm{a}}$ & 8 \\
\hline & De Oliveira et al. $[23]^{\mathrm{c}}$ & 125 \\
\hline & Sillanpää et al. [86] ${ }^{\mathrm{c}}$ & 32 \\
\hline & Balcarek et al. $[10]^{\mathrm{c}}$ & 73 \\
\hline & Balcarek et al. [9] ${ }^{\mathrm{c}}$ & 43 \\
\hline & Yoo et al. $[104]^{\mathrm{d}}$ & 10 \\
\hline & Enderlein et al. $[30]^{\mathrm{e}}$ & 240 \\
\hline & Tateishi et al. $[94]^{\mathrm{e}}$ & 27 \\
\hline & Bitar et al. $[15]^{\mathrm{e}}$ & 41 \\
\hline & Wijdicks et al. $[102]^{\mathrm{f}}$ & 11 \\
\hline & Nomura et al. [59] ${ }^{\mathrm{b}}$ & 27 \\
\hline \multirow[t]{3}{*}{ MFE and AT } & Iwama et al. $[42]^{\mathrm{c}}$ & 25 \\
\hline & Aragão et al. [4] $]^{\mathrm{a}}$ & 17 \\
\hline & Triantafillopoulos et al. [97] ${ }^{\mathrm{a}}$ & 8 \\
\hline Anterior to MFE & Feller et al. [32] ${ }^{\mathrm{a}}$ & 20 \\
\hline $\begin{array}{l}\text { Adjacent to medial collat- } \\
\text { eral (MCL) insertion }\end{array}$ & Deie et al. $[22]^{\mathrm{e}}$ & 6 \\
\hline AT with MCL & Phornphutkul et al. [70] ${ }^{\mathrm{b}}$ & 5 \\
\hline
\end{tabular}

Table 5 continued

\begin{tabular}{|c|c|c|}
\hline Site & Papers & $\begin{array}{l}\text { Number } \\
\text { of knees }\end{array}$ \\
\hline \multirow[t]{3}{*}{ Between AT and MCL } & Christiansen et al. [19] $^{\mathrm{e}}$ & 42 \\
\hline & Avikainen et al. [8] $]^{\mathrm{e}}$ & 14 \\
\hline & Wissman et al. $[103]^{\mathrm{c}}$ & 10 \\
\hline With superficial MCL & Warren and Marshall [101] ${ }^{\mathrm{a}}$ & 154 \\
\hline $\begin{array}{l}\text { AT and MFE and superfi- } \\
\text { cial MCL }\end{array}$ & Desio et al. $[23]^{\mathrm{a}}$ & 9 \\
\hline $\begin{array}{l}\text { Over MFE, distal to AT, } \\
\text { partly to capsule }\end{array}$ & Inoue et al. $[41]^{\mathrm{g}}$ & 1 \\
\hline $\begin{array}{l}38 \% \text { of postero-anterior } \\
\text { distance and } 54 \% \text { of } \\
\text { distal-proximal distance } \\
\text { of condyle }\end{array}$ & Oka et al. $[63]^{\mathrm{d}}$ & 20 \\
\hline $\begin{array}{l}5 \mathrm{~mm} \text { anterior to posterior } \\
\text { cortex, } 3 \mathrm{~mm} \text { proximal } \\
\text { to apex with Blumen- } \\
\text { saat's line }\end{array}$ & Redfern et al. $[75]^{\mathrm{a}}$ & 8 \\
\hline Proximal to physis & Shea et al. $[83]^{\mathrm{a}}$ & 6 \\
\hline \multirow[t]{2}{*}{ 5-6 mm distal to physis } & Kepler et al. $[47]^{\mathrm{c}}$ & 44 \\
\hline & Lippacher and Nelitz [51] ${ }^{\mathrm{f}}$ & 27 \\
\hline
\end{tabular}

Study type: ${ }^{\mathrm{a}}$ Cadaveric; ${ }^{\mathrm{b}}$ Mixed; ${ }^{\mathrm{c}} \mathrm{MRI}$; ${ }^{\mathrm{d}}$ Simulation; ${ }^{\mathrm{e}}$ Series; ${ }^{\mathrm{f}} \mathrm{X}$-ray; ${ }^{g}$ Case report

$A T$ adductor tubercle, $M F E$ medial femoral condyle, $M C L$ medial collateral ligament

Another study which correlated magnetic resonance imaging (MRI) findings to histology reported that in two of five knees examined, the MPFL attached to the medial femoral epicondyle (MFE) with the medial collateral ligament (MCL) [27].

\section{Cadaveric studies}

The methodological assessment of the 33 cadaveric studies is shown in Table 2. Cadaveric studies were in knees which the authors believed to be normal, and different cadaveric preservation techniques were used, with eighteen fresh frozen, eight embalmed, two unpreserved and the remainder using more than one preservation method (five papers) or not describing the preservation technique used (four papers).

To determine possible variations in anatomy (particularly knee size and MPFL length) based on height of subjects or cadavers, the origin countries for papers were recorded, and particularly if they described the source of the cadavers for dissection studies. Only nine of the 33 cadaveric studies specifically stated where the knees were sourced from. 
For the others, even if all authors were from the same country, then this was recorded separately as cadavers may be obtained and transported from a different country.

In total amongst the 33 studies, there were 705 cadaveric knees (range 5-154, median 16). These were mostly adult knees (29/33 papers) given that paediatric cadavers (3/33 papers) are not readily available [33]. One study did not specify the age range [51]. For the purposes of this review, skeletal maturity was defined as closure of the distal femoral physis. Amongst the adult cadaveric studies, the median of the average ages reported amongst the 18 papers that provided this information was 71 (range 19-100) years and when number of patients was also given (12 papers), the weighted average was 75 years in this subset. Cadaveric specimens do not accurately reflect the age of the patients typically seen with patellar dislocation or instability as demonstrated by the largest case series in this review of 224 patients with a median age of 23 years [32]. Likewise, of the three paediatric groups, one was of children aged 1 month-11 years [83].

There were also discrepancies with gender representation in cadaveric studies. Of the studies of adults, only $18 / 33$ recorded the gender of subjects (158 male, 121 female), in contrast to the usual finding in patellofemoral instability of more female than male patients [37]. There was no significant difference in laterality of knees in the cadaveric papers.

\section{Quality assessment}

The results of the CASP assessment are presented in Tables 2, 3. The overall quality of the evidence was strong with several studies scoring highly in the quality analysis and overlap of results.

Recurrent weaknesses of the cadaveric literature were that none of the studies were based on a sample size calculation, the source of the cadaveric samples were only presented in $26 \%$ of papers and the observer or assessor was only defined in $12 \%$ of papers. Only two studies amongst the radiological and clinical based their sample size on a power calculation, the assessor was only defined in $29 \%$ of papers, observer reliability was ascertained in $21 \%$ of papers, and only $36 \%$ of studies recorded measures from multiple observations (Table 3).

\section{Anatomy of MPFL synthesis findings}

\section{MPFL identification rate}

Data on MPFL identification rate were given in 28 studies. Earlier studies reported that the MPFL was not identified in all knees, raising a question about whether it was always present. In this systematic review, documented identification of the MPFL varied from 35 to $92 \%$ in four studies, 24 studies described $100 \%$ identification of the MPFL and five did not specifically state the rate of identification, but did not report difficulty identifying the ligament.

\section{MPFL size}

Data on MPFL length were presented in 19 papers. There was no obvious relationship to country of origin, or method of study with both the shortest $(45 \mathrm{~mm})$ and the longest $(74 \mathrm{~mm})$ reported MPFL lengths being from Japan and China, respectively. A single USS review article had reported a length of $40 \mathrm{~mm}$ but did not state whether this value was actually measured and was therefore excluded [22]. The weighted MPFL mean length and the unweighted median of the averages were both $56 \mathrm{~mm}$. The reliability of reported length is in part dependent on the difficulty in measuring it. More specifically, it has a broad insertion onto the patella $20-30 \mathrm{~mm}$ wide, being largely on the proximal medial border, with some fibres extending to the lower third in a minority of cases [65]. Similarly, the femoral origin of the ligament covers an area of around 10-22 mm width [65]. With such broad attachment points, it is difficult to know whether the different studies were measuring the same length.

An MRI study reported a $0.1 \mathrm{~mm}$ greater thickness of the MPFL in men than in women $(1.0$ and $0.9 \mathrm{~mm}$, respectively), whilst another reported statistically significant $(p<0.001)$ increasing MPFL length when comparing normal, unstable and recurrently dislocating patellae at 49 , 54 and $64 \mathrm{~mm}$, respectively [23, 44]. In contrast, MPFL lengths from 47 to $72 \mathrm{~mm}$ were reported in normal knees so it is unclear whether there is a direct correlation between patellar stability and ligament length, particularly given differences in measurement methods [65, 72]. This difference was also not explained by source of specimens (both cadaveric) or preservation method (both fresh frozen).

Investigating normal and acute MPFL injury MRI scans, a Japanese study reported average lengths of 53 and $49 \mathrm{~mm}$ in normal men and women, whereas a Chinese publication reported average MPFL length of $59 \mathrm{~mm}$ in acute patellar dislocation $[44,48]$. This would seem, then, to support the concept that MPFL length is increased in patellar dislocation. What is not known is whether these patients dislocate because they had longer MPFLs or whether they had longer MPFLs because they have dislocated and the injured MPFL heals longer than it was prior to injury. There was evidence that the MPFL ruptured once elongated beyond 12-18 mm and so even a first episode of patellar dislocation would result in injury [2]. Although the Chinese paper did not provide length separately by gender, the distribution of participants in papers was not dissimilar, being 4:6 and 32:53 males to females, respectively. 


\section{Origin and insertion of the MPFL from the study cohorts}

There were only four paediatric studies and they were not easily comparable as one related to the patellar attachment alone and another publication by the same authors was related to the physis alone $[83,84]$. Of the two remaining paediatric papers, one reported attachment next to the superficial MCL attachment and the other in the sulcus between the adductor tubercle (AT) and the medial femoral epicondyle (MFE), which covers a similar area [24, 33].

Fifteen of the studies were of acute patellar dislocation, forty in normal knees, nine in recurrent dislocation and three were a mixture of acute and recurrent. Again, there was no significant difference in attachment points reported, with a mixture of locations given in each group.

Data on MPFL femoral origin were given in 33 papers and MPFL patellar insertion in 29 papers (Tables 4, 5). There was excellent correlation on the insertion of the MPFL onto the medial patella but some discordance regarding which part precisely (Table 4; Fig. 2). There is evidence that the MPFL fans out and may have attachments distributed along the medial border, with $13 \%$ upper third only, seven percent middle third only, $40 \%$ upper and middle thirds, $13 \%$ middle and lower thirds and $27 \%$ along the whole length [4]. The patellar insertion measures

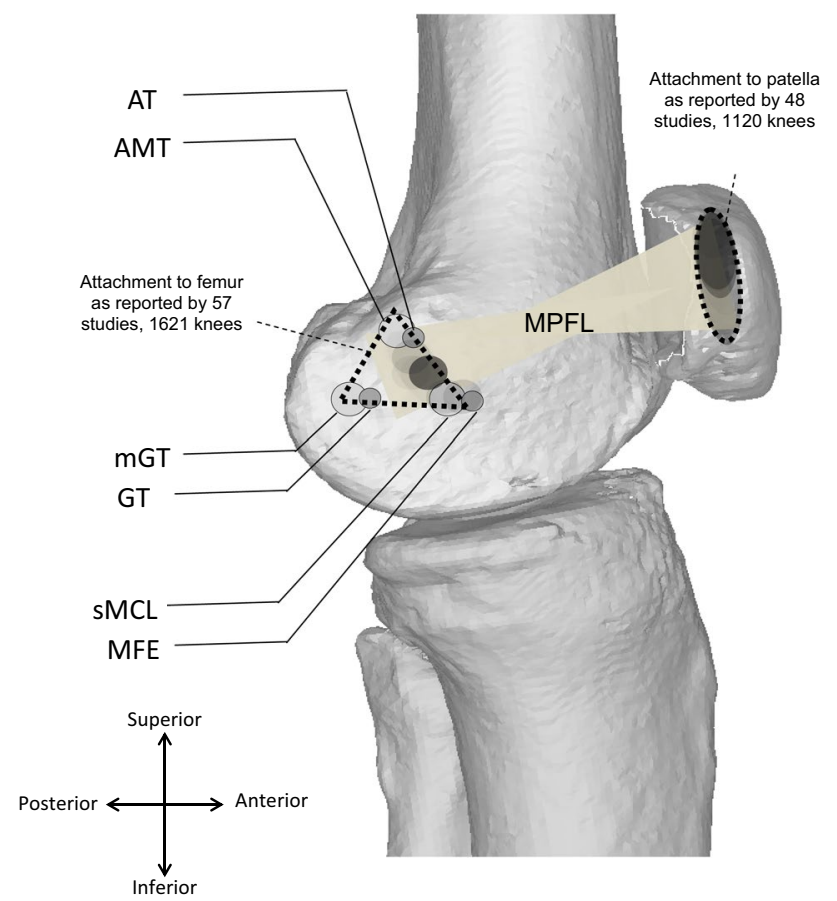

Fig. 2 Diagram summarising the MPFL attachment areas, darker shading represents study concordance. $A T$ adductor tubercle, $A M T$ adductor magnus tendon, $G T$ gastrocnemius tubercle, $m G T$ medial gastrocnemius tendon, $s M C L$ superficial medial collateral ligament, $M F E$ medial femoral condyle
$24 \pm 5$ (standard deviation, SD) $\mathrm{mm}$, and given that the articular surface of the patella is $46 \mathrm{~mm}$ long, there was overlap in reports of the patellar insertion (the insertion is half the length of the articular surface) [12, 67].

The greatest variations in anatomy described were of the femoral origin of the MPFL, with several sites reported in the literature (Table 5; Fig. 2). The size of the femoral origin itself varied with the width reported as $9-17 \mathrm{~mm} \mathrm{[4}$, $65,72]$. Compared to the width of the MFE and length of the MPFL itself, this is relatively large with the femoral attachment covering an area rather than a discrete point. To compare normal cadaveric knees to those with recurrent dislocation, the literature relevant to surgery for recurrent dislocation was reviewed. Many were excluded through screening as they referred to the MPFL origin without stating where this was found, or citing other papers $[40,85]$. Where given, the attachment was within similar boundaries and covered an area that was more posterior and proximal to the medial epicondyle [17].

\section{Discussion}

The most important finding of this review was that the MPFL originates between the medial femoral epicondyle, adductor tubercle and gastrocnemius tubercle and inserts on to the superomedial aspect of the patella with an average length of $56 \mathrm{~mm}$.

Studies have shown that a non-anatomical surgical reconstruction can lead to aberrant restraining forces and patellofemoral contact pressures [14, 26, 30]. Mal-positioning of the femoral insertion in the distal or proximal plane has been shown to have the most significant effect on isometry [93]. However, authors investigating the isometric and non-isometric attachment sites at the medial femoral epicondyle and adductor tubercle, respectively, did not find a significant difference in the contact pressures [57] and this may be explained by the relatively large attachment points that we have found with our systematic review. Use of the attachment areas (Fig. 2) rather than a specific point may be a truer representation of the normal anatomy, and this may provide a safe working window for graft attachment during MPFL reconstruction.

The literature search revealed no prior systematic reviews specifically investigating MPFL anatomy, and we are aware of only one review of the anatomy in 2015 with several more studies published on the subject in the interim. Their review had a number of limitations. The papers reviewed were limited chronologically to the 20 years prior to the literature search with a more limited search of the grey literature performed. Although the authors describe the mean length and the approximate area of the femoral attachment, there was no consensus given 
and it was difficult to translate this conclusion into a meaningful surgical planning tool [73]. Further, they stated that the MPFL had a 'sail type' shape, but in our wider review of the literature above, we have shown that it not only fans out at the patellar insertion but also at the femoral insertion, with a narrow central portion and is therefore shaped like an hourglass (Fig. 2).

Some issues also arise from nomenclature as the terminal part of the medial ridge of the linea aspera of the femur becomes the adductor tubercle. Previous studies have reported that publications have described the attachments interchangeably $[11,65]$ (regarding [93, 98]) [80].

Many of the studies looked at normal knees, not knees with patellar instability, and this may not be a true reflection of knees where the MPFL has been injured. Previous epidemiological studies demonstrated that patellar dislocation typically occurs during adolescence yet all but a handful of specifically paediatric studies using cadavers were in elderly adults $[37,96]$. There may be age-related changes in the ligament which should be considered given that some cases of recurrent instability are reported to improve without surgical intervention [6]. Within paediatric studies, there were differences in reporting (if measured proximal or distal to the physis) due to concavity of the growth plate [53]. Cadaveric studies do not reflect the gender bias with a 3:1 risk ratio for females to males aged 10-17 years for previous subluxation or dislocation, whereas cadaveric specimens were generally gender-balanced [37].

Imaging studies also have limitations, with both $\mathrm{CT}$ and MRI affected by partial volume loss between axial slices when the raw image data are obtained, and further losses within each slice from averaging algorithms. In addition, there was bias with more positive identification in patients with patellar dislocation or injury because the MPFL is more easily identified in patients with an effusion than in control patients [31]. In specialist studies, identification or exclusion of MPFL injuries using USS has been shown to have $100 \%$ sensitivity, specificity, negative and positive predictive values compared to subsequent surgical findings, and has the added advantage of dynamic imaging to look at the integrity of the ligament with respect to function [35].

Whilst studies have shown that the femoral fixation point in MPFL reconstruction is more important than the patellar fixation point, a non-anatomical femoral fixation point is not in isolation predictive of graft failure. Sanchis-Alfonso et al. investigated the influence of femoral fixation site on ligament dynamic changes and clinical outcome in 24 patients with 3D CT reconstruction. They found that out of 24 patients with a non-anatomical femoral graft fixation site, only four were defined as failures. Out of these four failures, three had anterior knee pain and only one had recurrent instability. They concluded that whilst reproducing an anatomical femoral fixation point was a reproducible way of achieving an optimal result, a non-anatomical femoral fixation site that reproduced graft isometry specifically during $0^{\circ}-30^{\circ}$ of flexion will still produce a satisfactory result [78]. This can also be explained by our study that has shown that the MPFL is hourglass in shape which may explain the satisfactory results obtained with previous studies investigating a 'nonanatomic' graft placement.

Warren and Marshall reported that the MPFL forms the inferior part of an anatomical space of triangular shape formed by the MPFL with the adductor magnus tendon (AMT) and the vastus medialis obliquus (VMO), with the femoral origin lying between MFE and AT [101], although the MPFL was not always easily identified.

One cadaveric dissection study included inspection for collateral knee structures in 20 cases, finding 13 had a lateral patellofemoral ligament (LPFL), and six of these also had a MPFL, whereas one specimen had a MPFL only [76]. They reported a finding of MPFL breadth of 5-12 mm in seven specimens. The MPFL superior border meets the oblique distal fibres of the vastus medialis obliquus, and there is wide variation in angle and differing origins and insertions, so there may be an underestimation of how often the MPFL is present. A 2008 study reported the ligament present in 15 of 17 cases (88\%) [4]. More recent studies have reported that the MPFL can be very thin, but is consistently seen at dissection $[2,16]$.

Knowledge of the anatomical origin and insertion points enables accurate assessment of potential injury and surgical repair or reconstruction, particularly in recurrent patellar dislocation. Understanding of key anatomical differences between normal and dislocation groups can guide surgical planning where lack of attention and understanding of attachment sites has been linked to a significant proportion of poor outcome in patients undergoing surgery [90].

Future studies with larger numbers of demographically linked (younger, proportionately more female) patients with and without patellar instability would be useful to confirm the findings of this systematic review. Whilst the instability group may be more easily available for surgical exploration, this will not represent the normal MPFL given the almost universal MPFL rupture rate from a single dislocation episode and the high rates of trochlear dysplasia.

\section{Conclusion}

The MPFL is hourglass in shape, originates from the medial femur and inserts onto the medial patellar border with an average length of $56 \mathrm{~mm}$.

Acknowledgements This study was supported by a grant from Orthopaedic Research UK. 
Authors' contributions AA, TOS, DT, $\mathrm{CH}$ : Study design, data analysis. AA, TOS, DT, CH, JC: Study write-up.

\section{Compliance with ethical standards}

Conflict of interests Mr Arash Aframian: None-MD(Res) student. Dr Smith: Grants in primary care research from South Norfolk Clinical Commissioning Group. Grants in patellofemoral instability research from Action Arthritis (Norfolk). Mr Tennent: Consultancy for and royalties from Arthrex. Miss Hing: ORUK (Orthopaedic Research UK) grants. AOUK (Arbeitsgemeinschaft für Osteosynthesefragen UK) grants. St George's Hospital Charity Grant. Editorial stipend Elsevier. Professor Cobb: Grants in hip surgery with DePuy. Advisory panel for hip preservation for Zimmer Biomet. Consultancy for hip arthroplasty for JRI. Consultancy for knee arthroplasty for Zimmer Biomet. Founder and shareholder for Embody. Founder and shareholder for Orthonika. Multi-centre grant for hip device with JRI. Royalties for knee arthroplasty with MatOrtho. Royalties for transcutaneous limb salvage device with Stanmore Orthopaedics.

Open Access This article is distributed under the terms of the Creative Commons Attribution 4.0 International License (http://creativecommons.org/licenses/by/4.0/), which permits unrestricted use, distribution, and reproduction in any medium, provided you give appropriate credit to the original author(s) and the source, provide a link to the Creative Commons license, and indicate if changes were made.

\section{References}

1. Ahmad CS, Shubin Stein BE, Matuz D, Henry JH (2000) Immediate surgical repair of the medial patellar stabilizers for acute patellar dislocation. A review of eight cases. Am J Sports Med 28:804-810

2. Amis AA, Firer P, Mountney J, Senavongse W, Thomas NP (2003) Anatomy and biomechanics of the medial patellofemoral ligament. Knee 10:215-220

3. Andrikoula S, Tokis A, Vasiliadis HS, Georgoulis A (2006) The extensor mechanism of the knee joint: an anatomical study. Knee Surg Sports Traumatol Arthrosc 14:214-220

4. Aragão JA, Reis FP, de Vasconcelos DP, Feitosa VLC, Nunes MAP (2008) Metric measurements and attachment levels of the medial patellofemoral ligament: an anatomical study in cadavers. Clinics (Sao Paulo) 63:541-544

5. Arendt EA, Fithian DC, Cohen E (2002) Current concepts of lateral patella dislocation. Clin Sports Med 21:499-519

6. Arnbjörnsson AH, Egund N, Rydling O, Stockerup R, Ryd L (1992) The natural history of recurrent dislocation of the patella. Long-term results of conservative and operative treatment. J Bone Joint Surg Br 74:140-142

7. Arthrex (2010) Medial Patellofemoral Ligament: Surgical Technique. http://www.arthrex.com/resources/surgical-technique-guide/sjjjx_kEEeCRTQBQVoRHOw/ medialpatellofemoral-ligament-mpfl

8. Avikainen VJ, Nikku RK, Seppänen-Lehmonen TK (1993) Adductor magnus tenodesis for patellar dislocation. Technique and preliminary results. Clin Orthop Relat Res 297:12-16

9. Balcarek P, Ammon J, Frosch S, Walde TA, Schüttrumpf JP, Ferlemann KG, Lill H, Stürmer KM, Frosch K-H (2010) magnetic resonance imaging characteristics of the medial patellofemoral ligament lesion in acute lateral patellar dislocations considering trochlear dysplasia, patella alta, and tibial tuberosity-trochlear groove distance. Arthroscopy 26:926-935
10. Balcarek P, Alexander T, Frosch S, Schüttrumpf JP, Wachowski MM, Stürmer KM, Frosch K-H (2011) Patellar dislocations in children, adolescents and adults: a comparative MRI study of medial patellofemoral ligament injury patterns and trochlear groove anatomy. Eur J Radiol 79:415-420

11. Baldwin JL (2009) The anatomy of the medial patellofemoral ligament. Am J Sports Med 37:2355-2361

12. Baldwin JL, House CK (2005) Anatomic dimensions of the patella measured during total knee arthroplasty. J Arthroplasty 20:250-257

13. Barnett AJ, Howells NR, Burston BJ, Ansari A, Clark D, Eldridge JD (2012) Radiographic landmarks for tunnel placement in reconstruction of the medial patellofemoral ligament. Knee Surg Sports Traumatol Arthrosc 20:2380-2384

14. Beck P, Brown NAT, Greis PE, Burks RT (2007) Patellofemoral contact pressures and lateral patellar translation after medial patellofemoral ligament reconstruction. Am J Sports Med 35:1557-1563

15. Bitar AC, Demange MK, D'Elia CO, Camanho GL (2012) Traumatic patellar dislocation: nonoperative treatment compared with MPFL reconstruction using patellar tendon. Am J Sports Med 40:114-122

16. Boden BP, Pearsall AW, Garrett W, Feagin J (1997) Patellofemoral instability: evaluation and management. J Am Acad Orthop Surg 5:47-57

17. Camanho GL, Bitar AC, Hernandez AJ, Olivi R (2007) Medial patellofemoral ligament reconstruction: a novel technique using the patellar ligament. Arthroscopy 23:108.e1-108.e4

18. Camanho GL, Ph D, Viegas ADC, Sc M, Bitar AC, Sc M, Demange MK, Sc M, Hernandez AJ, Ph D (2009) Conservative versus surgical treatment for repair of the medial patellofemoral ligament in acute dislocations of the patella. Arthroscopy 25:620-625

19. Christiansen SE, Jakobsen BW, Lund B, Lind M (2008) Isolated repair of the medial patellofemoral ligament in primary dislocation of the patella: a prospective randomized study. Arthroscopy 24:881-887

20. Cofield RH, Bryan RS (1977) Acute dislocation of the patella: results of conservative treatment. J Trauma 17:526-531

21. Conlan T, Garth WP, Lemons JE (1993) Evaluation of the medial soft-tissue restraints of the extensor mechanism of the knee. J Bone Joint Surg Am 75:682-693

22. De Maeseneer M, Marcelis S, Boulet C, Kichouh M, Shahabpour M, de Mey J, Cattrysse E (2014) Ultrasound of the knee with emphasis on the detailed anatomy of anterior, medial, and lateral structures. Skeletal Radiol 43:1025-1039

23. De Oliveira V, De Souza V, Cury R, Camargo OP, Avanzi O, Severino N, Fucs P (2014) Medial patellofemoral ligament anatomy: is it a predisposing factor for lateral patellar dislocation? Int Orthop 38:1633-1639

24. Deie M, Ochi M, Sumen Y, Yasumoto M, Kobayashi K, Kimura $\mathrm{H}$ (2003) Reconstruction of the medial patellofemoral ligament for the treatment of habitual or recurrent dislocation of the patella in children. J Bone Joint Surg Br 85:887-890

25. Desio SM, Burks RT, Bachus KN (1998) Soft tissue restraints to lateral patellar translation in the human knee. Am J Sports Med 26:59-65

26. DeVries Watson N, Duchman KR, Bollier MJ, Grosland NM (2015) A finite element analysis of medial patellofemoral ligament reconstruction. Iowa Orthop J 35:13-19

27. Dirim B, Haghighi P, Trudell D, Portes G, Resnick D (2008) Medial patellofemoral ligament: cadaveric investigation of anatomy with MRI, MR arthrography, and histologic correlation. Am J Roentgenol 191:490-498

28. Dirisamer F, Anderl C, Liebensteiner M, Hochreiter J (2014) Operative Therapie der isolierten patellofemoralen Arthrose. Orthopade 43:432-439 
29. Duchman KR, DeVries N, McCarthy M, Kuiper JJ, Grosland NM, Bollier MJ (2013) Biomechanical evaluation of medial patellofemoral ligament reconstruction. Iowa Orthop J 33:64-69

30. Elias JJ, Cosgarea AJ (2006) Technical errors during medial patellofemoral ligament reconstruction could overload medial patellofemoral cartilage: a computational analysis. Am J Sports Med 34:1478-1485

31. Elias DA, White LM, Fithian DC (2002) Acute lateral patellar dislocation at MR imaging: injury patterns of medial patellar soft-tissue restraints and osteochondral injuries of the inferomedial patella. Radiology 225:736-743

32. Enderlein D, Nielsen T, Christiansen SE, Faun $\varnothing$ P, Lind M (2014) Clinical outcome after reconstruction of the medial patellofemoral ligament in patients with recurrent patella instability. Knee Surg Sports Traumatol Arthrosc 22:2458-2464

33. Farrow LD, Alentado VJ, Abdulnabi Z, Gilmore A, Liu RW (2014) The relationship of the medial patellofemoral ligament attachment to the distal femoral physis. Am J Sports Med 42:2214-2218

34. Feller MJ, Feagin JA Jr, Garrett WE Jr (1993) The medial patellofemoral ligament revisited: an anatomical study. Knee Surg Sports Traumatol Arthrosc 1:184-186

35. Felus J, Kowalczyk B (2012) Age-related differences in medial patellofemoral ligament injury patterns in traumatic patellar dislocation: case series of 50 surgically treated children and adolescents. Am J Sports Med 40:2357-2364

36. Felus J, Kowalczyk B, Lejman T (2008) Sonographic evaluation of the injuries after traumatic patellar dislocation in adolescents. J Pediatr Orthop 28:397-402

37. Fithian DC, Paxton EW, Lou Stone M, Silva P, Davis DK, Elias DA, White LM (2004) Epidemiology and natural history of acute patellar dislocation. Am J Sports Med 32:1114-1121

38. Frosch S, Balcarek P, Walde TA, Schüttrumpf JP, Wachowski MM, Ferleman K-G, Stürmer KM, Frosch K-H (2011) The treatment of patellar dislocation: a systematic review. Z Orthop Unfall 149:630-645

39. Fujino K, Tajima G, Yan J, Kamei Y, Maruyama M, Takeda S, Kikuchi S, Shimamura T (2015) Morphology of the femoral insertion site of the medial patellofemoral ligament. Knee Surg Sports Traumatol Arthrosc 23:998-1003

40. Goorens CK, Robijn H, Hendrickx B, Delport H, De Mulder K, Hens J (2010) Reconstruction of the medial patellofemoral ligament for patellar instability using an autologous gracilis tendon graft. Acta Orthop Belg 76:398-402

41. Graf M, Diether S, Vlachopoulos L, Fucentese S, Fürnstahl P (2014) Automatic string generation for estimating in vivo length changes of the medial patellofemoral ligament during knee flexion. Med Biol Eng Comput 52:511-520

42. Hautamaa PV, Fithian DC, Kaufman KR, Daniel DM, Pohlmeyer AM (1998) Medial soft tissue restraints in lateral patellar instability and repair. Clin Orthop Relat Res 349:174-182

43. Inoue M, Nomura E, Sugiura H, Kobayashi S (2006) Histological findings of avulsion tear-type medial patellofemoral ligament injury in acute patellar dislocation. J Clin Pathol 60:1068-1069

44. Iwama Y, Fujii M, Shibanuma H, Muratsu H, Kurosaka M, Kawamitsu H, Sugimura K (2006) High-resolution MRI using a microscopy coil for the diagnosis of recurrent lateral patellar dislocation. Radiat Med Med Imaging Radiat Oncol $24: 327-334$

45. Iwano T, Kurosawa H, Tokuyama H, Hoshikawa Y (1990) Roentgenographic and clinical findings of patellofemoral osteoarthrosis. With special reference to its relationship to femorotibial osteoarthrosis and etiologic factors. Clin Orthop Relat Res 252:190-197

46. Jacobi M, Reischl N, Bergmann M, Bouaicha S, Djonov V, Magnussen RA (2012) Reconstruction of the medial patellofemoral ligament using the adductor magnus tendon: an anatomic study. Arthroscopy 28:105-109

47. Kang HJ, Wang F, Chen BC, Su YL, Zhang ZC, Yan CB (2010) Functional bundles of the medial patellofemoral ligament. Knee Surg Sports Traumatol Arthrosc 18:1511-1516

48. Kang HJ, Wang F, Chen BC, Zhang YZ, Ma L (2013) Nonsurgical treatment for acute patellar dislocation with special emphasis on the MPFL injury patterns. Knee Surg Sports Traumatol Arthrosc 21:325-331

49. Kepler CK, Bogner EA, Hammoud S, Malcolmson G, Potter HG, Green DW (2011) Zone of injury of the medial patellofemoral ligament after acute patellar dislocation in children and adolescents. Am J Sports Med 39:1444-1449

50. LaPrade RF, Engebretsen AH, Ly TV, Johansen S, Wentorf FA, Engebretsen L (2007) The anatomy of the medial part of the knee. J Bone Joint Surg Am 89:2000-2010

51. Lee HS, Choi JY, Ha JK, Lee YS, Yoo JH, Kim MK, Kim JG (2011) Anatomical reconstruction of the medial patellofemoral ligament: development of a novel procedure based on anatomical dissection. J Korean Orthop Assoc 46:443

52. Lim AKS, Chang HC, Hui JHP (2008) Recurrent patellar dislocation: reappraising our approach to surgery. Ann Acad Med Singapore 37:320-323

53. Lippacher S, Nelitz M (2012) Femorale Insertion des medialen patellofemoralen Ligaments in Relation zur distalen femoralen Wachstumsfuge [The femoral insertion of the medial patellofemoral ligament in relation to the distal femoral growth plate]. Arthroskopie 25:275-279

54. Macnab I (1952) Recurrent dislocation of the patella. J Bone Joint Surg Am 34:957-967 (passim)

55. Mäenpää H, Huhtala H, Lehto MUK (1997) Recurrence after patellar dislocation. Acta Orthop Scand 68:424-426

56. Matthews JJ, Schranz P (2010) Reconstruction of the medial patellofemoral ligament using a longitudinal patellar tunnel technique. Int Orthop 34:1321-1325

57. Melegari TM, Parks BG, Matthews LS (2008) Patellofemoral contact area and pressure after medial patellofemoral ligament reconstruction. Am J Sports Med 36:747-752

58. Mochizuki T, Nimura A, Tateishi T, Yamaguchi K, Muneta T, Akita K (2013) Anatomic study of the attachment of the medial patellofemoral ligament and its characteristic relationships to the vastus intermedius. Knee Surg Sports Traumatol Arthrosc 21:305-310

59. Moher D, Liberati A, Tetzlaff J, Altman DG, The PRISMA Group (2009) Preferred reporting items for systematic reviews and meta-analyses: the PRISMA statement (Reprinted from Annals of Internal Medicine). PLOS Med 6(e1000097):1-6

60. Nomura E, Inoue M (2006) Hybrid medial patellofemoral ligament reconstruction using the semitendinous tendon for recurrent patellar dislocation: minimum 3 years' follow-up. Arthroscopy 22:787-793

61. Nomura E, Horiuchi Y, Kihara M (2000) Medial patellofemoral ligament restraint in lateral patellar translation and reconstruction. Knee 7:121-127

62. Nomura E, Horiuchi Y, Inoue M (2002) Correlation of MR imaging findings and open exploration of medial patellofemoral ligament injuries in acute patellar dislocations. Knee 9:139-143

63. Nomura E, Inoue M, Osada N (2005) Anatomical analysis of the medial patellofemoral ligament of the knee, especially the femoral attachment. Knee Surg Sports Traumatol Arthrosc 13:510-515 
64. Oka S, Matsushita T, Kubo S, Matsumoto T, Tajimi H, Kurosaka M, Kuroda R (2014) Simulation of the optimal femoral insertion site in medial patellofemoral ligament reconstruction. Knee Surg Sports Traumatol Arthrosc 22:2364-2371

65. Panagiotopoulos E, Strzelczyk P, Herrmann M, Scuderi G (2006) Cadaveric study on static medial patellar stabilizers: the dynamizing role of the vastus medialis obliquus on medial patellofemoral ligament. Knee Surg Sports Traumatol Arthrosc 14:7-12

66. Panagopoulos A, van Niekerk L, Triantafillopoulos I (2008) MPFL reconstruction for recurrent patella dislocation: a new surgical technique and review of the literature. Int J Sports Med 29:359-365

67. Philippot R, Chouteau J, Wegrzyn J, Testa R, Fessy MH, Moyen B (2009) Medial patellofemoral ligament anatomy: implications for its surgical reconstruction. Knee Surg Sports Traumatol Arthrosc 17:475-479

68. Philippot R, Chouteau J, Farizon F, Moyen B (2011) Anatomy of the medial patellofemoral ligament and implications for its surgical reconstruction. J Bone Joint Surgery Br 93:507

69. Philippot R, Boyer B, Testa R, Farizon F, Moyen B (2012) Study of patellar kinematics after reconstruction of the medial patellofemoral ligament. Clin Biomech 27:22-26

70. Phornphutkul C, Sekiya JK, Wojtys EM, Jacobson JA (2007) Sonographic imaging of the patellofemoral medial joint stabilizing structures: findings in human cadavers. Orthopedics 30:472-478

71. Pinskerova V, Maquet P, Freeman M (2000) Writings on the knee between 1836 and 1917. J Bone Joint Surg Br 82:1100-1102

72. Placella G, Tei MM, Sebastiani E, Criscenti G, Speziali A, Mazzola C, Georgoulis A, Cerulli G (2014) Shape and size of the medial patellofemoral ligament for the best surgical reconstruction: a human cadaveric study. Knee Surg Sports Traumatol Arthrosc 22:2327-2333

73. Placella G, Tei M, Sebastiani E, Speziali A, Antinolfi P, Delcogliano M, Georgoulis A, Cerulli G (2015) Anatomy of the medial patello-femoral ligament: a systematic review of the last 20 years literature. Musculoskelet Surg Milan 99:93-103

74. Reagan J, Kullar R, Burks R (2015) MPFL reconstruction technique and results. Orthop Clin North Am 46:159-169

75. Redfern J, Kamath G, Burks R (2010) Anatomical confirmation of the use of radiographic landmarks in medial patellofemoral ligament reconstruction. Am J Sports Med 38:293-297

76. Reider B, Marshall JL, Koslin B, Ring B, Girgis FG (1981) The anterior aspect of the knee joint. J Bone Joint Surg Am 63:351-356

77. Sallay PI, Poggi J, Speer KP, Garrett WE (1995) Acute dislocation of the patella. A correlative pathoanatomic study. Am J Sports Med 24:52-60

78. Sanchis-Alfonso V, Ramirez-Fuentes C, Montesinos-Berry E, Domenech J, Martí-Bonmatí L (2015) Femoral insertion site of the graft used to replace the medial patellofemoral ligament influences the ligament dynamic changes during knee flexion and the clinical outcome. Knee Surg Sports Traumatol Arthrosc 1-9. doi:10.1007/s00167-015-3905-0

79. Schottle PB, Schmeling A, Rosenstiel N, Weiler A (2007) Radiographic landmarks for femoral tunnel placement in medial patellofemoral ligament reconstruction. Am J Sports Med 35:801-804

80. Schöttle PB, Fucentese SF, Romero J (2005) Clinical and radiological outcome of medial patellofemoral ligament reconstruction with a semitendinosus autograft for patella instability. Knee Surg Sports Traumatol Arthrosc 13:516-521

81. Schöttle PB, Hensler D, Imhoff AB (2010) Anatomical doublebundle MPFL reconstruction with an aperture fixation. Knee Surg Sports Traumatol Arthrosc 18:147-151
82. Senavongse W, Amis AA (2005) The effects of articular, retinacular, or muscular deficiencies on patellofemoral joint stability. J Bone Joint Surg Br 87:577-582

83. Shea KG, Polousky JD, Jacobs JC, Ganley TJ, Aoki SK, Grimm NL, Parikh SN (2014) The relationship of the femoral physis and the medial patellofemoral ligament in children: a cadaveric study. J Pediatr Orthop 34:808-813

84. Shea KG, Polousky JD, Jacobs JC, Ganley TJ, Aoki SK, Grimm NL, Parikh SN (2015) The patellar insertion of the medial patellofemoral ligament in children: a cadaveric study. J Pediatr Orthop 35:e31-e35

85. Siebold R, Borbon CAV (2012) Arthroscopic extraarticular reconstruction of the medial patellofemoral ligament with gracilis tendon autograft-surgical technique. Knee Surg Sports Traumatol Arthrosc 20:1245-1251

86. Sillanpää PJ, Peltola E, Mattila VM, Kiuru M, Visuri T, Pihlajamäki H (2009) Femoral avulsion of the medial patellofemoral ligament after primary traumatic patellar dislocation predicts subsequent instability in men: a mean 7-year nonoperative follow-up study. Am J Sports Med 37:1513-1521

87. Sillanpää PJ, Salonen E, Pihlajamäki H, Mäenpää HM (2014) Medial patellofemoral ligament avulsion injury at the patella: classification and clinical outcome. Knee Surg Sports Traumatol Arthrosc 22:2414-2418

88. Smirk C, Morris H (2003) The anatomy and reconstruction of the medial patellofemoral ligament. Knee 10:221-227

89. Smith TO, Nichols R, Harle D, Donell ST (2009) Do the vastus medialis obliquus and vastus medialis longus really exist? A systematic review. Clin Anat 22:183-199

90. Spritzer CE, Courneya DL, Burk DL, Garrett WE, Strong JA (1997) Medial retinacular complex injury in acute patellar dislocation: MR findings and surgical implications. Am J Roentgenol 168:117-122

91. Starok M, Lenchik L, Trudell D, Resnick D (1997) Normal patellar retinaculum: MR and sonographic imaging with cadaveric correlation. Am J Roentgenol 168:1493-1499

92. Steensen RN, Dopirak RM, McDonald WG (2004) The anatomy and isometry of the medial patellofemoral ligament: implications for reconstruction. Am J Sports Med 32:1509-1513

93. Stephen JM, Lumpaopong P, Deehan DJ, Kader D, Amis AA (2012) The medial patellofemoral ligament: location of femoral attachment and length change patterns resulting from anatomic and nonanatomic attachments. Am J Sports Med 40:1871-1879

94. Tateishi T, Tsuchiya M, Motosugi N, Asahina S, Ikeda H, Cho S, Muneta T (2011) Graft length change and radiographic assessment of femoral drill hole position for medial patellofemoral ligament reconstruction. Knee Surg Sports Traumatol Arthrosc 19:400-407

95. Thaunat M, Erasmus PJ (2009) Management of overtight medial patellofemoral ligament reconstruction. Knee Surg Sports Traumatol Arthrosc 17:480-483

96. Tompkins MA, Arendt EA (2015) Patellar instability factors in isolated medial patellofemoral ligament reconstructions-what does the literature tell us?: a systematic review. Am J Sports Med 43:2318-2327

97. Triantafillopoulos IK, Panagopoulos A, van Niekerk L (2007) Isometric behavior of the reconstructed medial patellofemoral ligament using two different femoral pulleys: a cadaveric study. Med Sci Monit 13:BR181-R187

98. Tuxøe JI, Teir M, Winge S, Nielsen PL (2002) The medial patellofemoral ligament: a dissection study. Knee Surg Sports Traumatol Arthrosc 10:138-140

99. Viste A, Chatelet F, Desmarchelier R, Fessy M-H (2014) Anatomical study of the medial patello-femoral ligament: landmarks for its surgical reconstruction. Surg Radiol Anat 36:733-739 
100. Waligora AC, Johanson NA, Hirsch BE (2009) Clinical anatomy of the quadriceps femoris and extensor apparatus of the knee. Clin Orthop Relat Res 467:3297-3306

101. Warren LF, Marshall JL (1979) The supporting structures and layers on the medial side of the knee: an anatomical analysis. $\mathrm{J}$ Bone Joint Surg Am 61:56-62

102. Wijdicks CA, Griffith CJ, LaPrade RF, Johansen S, Sunderland A, Arendt EA, Engebretsen L (2009) Radiographic identification of the primary medial knee structures. J Bone Joint Surg Am 91:521-529

103. Wissman RD, Verma S, Kreeger M, Robertson M (2009) Extensor mechanism injuries in tibiofemoral dislocations. J Comput Assist Tomogr 33:145-149
104. Yoo Y, Chang HG, Seo Y, Byun JC, Lee GK, Im H, Song SY (2012) Changes in the length of the medial patellofemoral ligament: an in vivo analysis using 3-dimensional computed tomography. Am J Sports Med 40:2142-2148

105. Zhang GY, Zheng L, Shi H, Qu SH, Ding HY (2013) Sonography on injury of the medial patellofemoral ligament after acute traumatic lateral patellar dislocation: injury patterns and correlation analysis with injury of articular cartilage of the inferomedial patella. Injury 44:1892-1898 